\title{
Direitos humanos e equidade: um olhar sobre as políticas de ações afirmativas na educação superior no Brasil
}

\author{
Human rights and equity: \\ a look at the policies of affirmative action \\ in higher education in Brazil
}

\begin{abstract}
Maria Couto Cunha ${ }^{1}$
mariacoutocunha@gmail.com

Penildon Silva Filho ${ }^{2}$

silvafilhopenildon@yahoo.com.br

Eudes Oliveira Cunha ${ }^{3}$

eudesocunha@gmail.com
\end{abstract}

\section{Resumo}

O presente artigo desenvolve uma discussão sobre os direitos humanos e sobre as políticas de ações afirmativas efetivadas por universidades públicas brasileiras, a partir da produção acadêmica. Inicia trazendo contribuições no campo do conhecimento sobre os direitos humanos, com ênfase nos princípios da igualdade, equidade, justiça social e respeito às diferenças. Reporta aos resultados de alguns estudos que analisam experiências de políticas de ações afirmativas, com foco em programas implementados em instituições de educação superior públicas no Brasil, como estratégia para a promoção da equidade. Os estudos sinalizam os efeitos positivos dessa política, apesar de se compreender a importância da adoção concomitante de políticas universalistas como essencial para favorecer a democratização do acesso nesse nível de educação.

Palavras-chave: direitos humanos; educação superior; equidade; ação afirmativa; respeito à diferença.

\section{Abstract}

This article develops a discussion on human rights and the affirmative action policies carried out by Brazilian public universities, from the academic production. It starts bringing contributions to the studies on human rights, focusing on the principles of equality, equity, social justice and respect for differences. It reports the results of some studies that examine the experiences of affirmative action policies, focusing on programs implemented in public higher education institutions in Brazil, as a strategy to promote equity. The studies indicate the positive effects of this policy, although

\footnotetext{
1 Professora da Faculdade de Educação da Universidade Federal da Bahia (UFBA), vinculada à linha de pesquisa Política e Gestão da Educação.

2 Doutor em Educação pela Universidade Federal da Bahia (UFBA). Professor vinculado à linha de pesquisa Política e Gestão da Educação do Programa de Pós-graduação em Educação da UFBA.

${ }^{3}$ Doutorando em Educação pela Universidade Federal da Bahia (UFBA). Mestre em Educação (UFBA). É professor da rede pública de ensino do município de Salvador-BA.
}

Revista Educação Online, n. 16, mai-ago 2014, p. 66-89 
they understand the importance of concomitant adoption of universal policies as vital to promote the democratization of accessing this level of education.

Keywords: human rights, higher education, equity, affirmative action, respect for difference.

\section{Introdução}

A partir dos anos 2000, no Brasil, intensificaram-se as discussões entre estudiosos, educadores, docentes das instituições de ensino, dirigentes do sistema educacional do país, população em geral, com a participação significativa dos movimentos sociais, sobre a necessidade de políticas de ações afirmativas diante das desigualdades históricas de acesso dos candidatos às universidades públicas, levando em conta suas condições de classe, de raça e de etnia. Uma das justificativas para a implantação das políticas de ações afirmativas baseia-se no fundamento de que há uma dívida histórica com relação a grupos considerados minoritários e, por isso, as políticas públicas devem também voltar-se para a diminuição das desigualdades, ou seja, direcionadas à efetivação da igualdade substantiva, conforme denominam alguns teóricos (GUIMARÃES, 2012; GOMES, 2001). De acordo com Gomes e Silva (2001, p. 94),

as ações afirmativas podem ser definidas como um conjunto de políticas públicas e privadas de caráter compulsório, facultativo ou voluntário, concebidas com vistas ao combate à discriminação racial, de gênero, por deficiência física e de origem nacional, bem como para corrigir ou mitigar os efeitos presentes da discriminação praticada no passado, tendo por objetivo a concretização do ideal de efetiva igualdade de acesso a bens fundamentais como a educação e o emprego.

Assim, as ações afirmativas podem ser compreendidas também como ações que buscam a correção de uma situação de discriminação e desigualdade em que se encontram determinados grupos sociais.

Piovesan (2005), ao discutir as ações afirmativas na perspectiva dos direitos humanos, salienta que os debates acerca do respeito às diferenças intensificaramse com a definição dos direitos humanos, firmados, sobretudo, no século $X X$, identificando aí uma segunda justificativa para as políticas de ação afirmativa, erigidas sobre o conceito de diversidade. Para Piovesan (2005), torna-se

insuficiente tratar o indivíduo de forma genérica, geral e abstrata. Faz-se necessária a especificação do sujeito de direito, que passa a ser visto em sua peculiaridade e particularidade. Nessa ótica, determinados sujeitos de direito ou determinadas violações de direitos exigem uma resposta específica e diferenciada. (p. 46) 
O reconhecimento das particularidades dos sujeitos de direito conduziu o Estado a buscar formas específicas de enfrentamento das desigualdades sociais. Nesse sentido, o conceito de igualdade formal passou a ser questionado, dando espaço para concepções que valorizam o tratamento desigual aos desiguais.

Feres Júnior (2007) amplia o debate acerca das justificações das políticas de ação afirmativa, as quais, para o autor, normalmente se baseiam na reparação histórica, na justiça social e na diversidade, especificamente quando discute as experiências dos Estados Unidos e do Brasil, por sua proximidade histórica e pela influência norte-americana no debate e na academia brasileira. Nesse sentido, é comum encontrarmos nas argumentações em favor das políticas de ação afirmativa uma ênfase ou prioridade em um desses eixos.

Vê-se que, no caso da reparação, "as iniciativas visam a restituir ou mitigar perdas provenientes de injúria ou crime do passado" (p. 86). O termo justiça social "aplica-se ao argumento de que qualquer desigualdade injustificada constitui de fato uma injustiça que potencialmente deve ser, de alguma maneira, mitigada por ação estatal" (p. 86). Já o argumento da diversidade é baseado, muitas vezes, "no suposto ganho de qualidade de ensino e de serviço que um corpo estudantil formado por pessoas de diversas origens sociais e culturais proporcionaria" (FERES JÚNIOR; CAMPOS, 2013, p. 86-87).

Nesse contexto, em que são colocadas em debate estratégias e justificativas para a efetivação de políticas que visam à redução das desigualdades sociais, a busca pela equidade no acesso à universidade pública ganha destaque com programas de reserva de vagas, bônus ou acréscimo de vagas para determinados grupos. No bojo dessa discussão, levantam-se questões acerca das concepções teóricas sobre igualdade, as quais fundamentam políticas públicas voltadas para a diminuição das desigualdades sociais e os efeitos da política de ações afirmativas para a educação superior no contexto brasileiro.

Identificamos que o debate público das políticas de ação afirmativa se processa no Brasil no contexto do fortalecimento da democracia, notadamente com a promulgação da Constituição de 1988 e leis infraconstitucionais. O presente artigo propõe uma discussão, a partir da produção acadêmica acerca dessa temática, iniciando por compreender as bases que fundamentam essas políticas. Em seguida, 
reporta a alguns estudos que analisam experiências de políticas de ações afirmativas, com foco em programas implementados em instituições de educação superior públicas no Brasil, como estratégia para a promoção da equidade nesse nível de educação.

\section{Concepções de igualdade sob a ótica dos direitos humanos}

O debate sobre a igualdade e equidade na sociedade ganha relevo quando se debatem os direitos humanos. Esses, compreendidos como construção historicamente determinada, que se reconfiguram a partir das mudanças culturais proporcionadas pelas transformações sociais e políticas, vêm afirmando-se como princípios para o combate às desigualdades, injustiças, exclusões e dominações ao longo da história.

Os direitos humanos vêm se constituindo como campo de realização da justiça social, sem distinção de nação, raça, Estado, gênero, orientação sexual, etnia, condição física ou idade. Esse "patrimônio" da humanidade foi construído ao longo da história, através de movimentos sociais, reivindicações e lutas, que fizeram avançar legislações, compreensões culturais sobre o que a sociedade considera justo, levando em consideração as configurações econômicas e territoriais dos povos.

Uma discussão que está explicitada com força é aquela que estabelece a igualdade material, ou igualdade substantiva, como superior à igualdade formal (GOMES, 2003; CASHMORE, 2000; SILVÉRIO, 2003). A igualdade formal foi conquistada com as revoluções burguesas, nos séculos XVII e XVIII, especificamente com a Revolução Inglesa, a Revolução Americana e a Revolução Francesa, com a liberalização da economia. Esse Estado liberal se consolidaria nos séculos $X I X$ e $X X$.

Contudo, a igualdade formal, que significou um avanço em relação ao momento anterior, não garantiu por si a igualdade material, ou substantiva, uma vez que a não intervenção do Estado no âmbito das relações econômicas e sociais acabou por reproduzir as injustiças e concentrações de poder e de renda, beneficiando alguns em detrimento de outros. Todo o processo histórico-social de assimetrias não pode ser revertido apenas com a aplicação equânime de leis que versam apenas sobre os direitos civis e políticos. 
O mercado e a sociedade carregam dentro de si as contradições e as injustiças decorrentes do processo histórico do conflito de classe, de grupos, de gênero e etnias ou outra forma de segmentação. Essas situações de desigualdades e injustiças, construídas socialmente, não encontram na igualdade formal do liberalismo político e econômico a sua superação. A igualdade formal se consolidou como um avanço em relação à sociedade de estamentos e castas (LIMA, 2009). No entanto, essa mesma igualdade pode produzir injustiças, se outros fatores do ponto de vista sócio-histórico não forem considerados. Assim, outras ponderações aparecem nos novos cenários da contemporaneidade, que objetivam superar os limites desse liberalismo.

\section{Equidade, justiça social $e$ o respeito às diferenças}

Conforme referido, as oportunidades eram concedidas a uma parte de indivíduos socialmente privilegiados. Importaria, pois, colocar o contingente de indivíduos socialmente desfavorecidos no mesmo nível de partida na disputa social. Nesse sentido, em vez de igualdade legal, importaria falar em igualdade de condições e de oportunidades (DRAY, 1999).

É nesse debate, que surge a questão da "equidade", compreendida por Dray como igualdade de oportunidades, e não somente igualdade perante a lei. Lima e Rodríguez (2008, p. 10) salientam que o conceito de equidade necessita ser esclarecido, pois "a aplicação prática de 'tratar de forma igual os desiguais' produz resultados diferentes de "tratar de forma desigual os desiguais", sendo que essa última forma é que caracterizaria a equidade. Com efeito, entende-se que o sentido da equidade diz respeito à promoção da justiça social, por meio do tratamento diferenciado dos sujeitos, na busca pela igualdade de resultados. Com relação à política de cotas em universidades públicas brasileiras, por exemplo, essas representam a tentativa de romper com uma situação de desigualdade, principalmente, entre pobres e ricos, assim como entre negros e brancos, e são formuladas com o fundamento do princípio da equidade, na promoção da igualdade.

Para Sposati (2002, p. 6, apud Gomes, 2011, p. 11), equidade é entendida como:

o reconhecimento e a efetivação, com igualdade, dos direitos da população, sem restringir o acesso a eles nem estigmatizar as diferenças que conformam os diversos segmentos que a compõem. Assim, equidade é entendida como possibilidade das 
diferenças serem manifestadas e respeitadas, sem discriminação, condição que favorece o combate das práticas de subordinação ou de preconceito em relação às diferenças de gênero, políticas, étnicas, religiosas, culturais, de minorias etc.

Essa concepção da equidade acima está mais inscrita na justificativa da "diversidade" para as políticas de ação afirmativa, embora possamos entender a equidade também sob o prisma da justiça social, para a promoção de redistribuição de bens para grupos socialmente desprivilegiados.

A falta de equidade é caracterizada como "assimetria". No Relatório anual das desigualdades raciais no Brasil (CARVALHO; PAIXÃO, 2008), essa antítese surge com muita clareza: equidade como oposto de assimetria. O referido relatório tem como principal objetivo "sistematizar e refletir sobre avanços e recuos da equidade racial e de gênero no país em seus diversos aspectos" e tem o interesse em proceder "estudos das assimetrias raciais no Brasil" (CARVALHO; PAIXÃO, 2008, p.13).

Rodrigo de Jesus (2011) trata também da questão da equidade, estabelecendo que, assim como a igualdade está para o Estado liberal e para a formalidade, a equidade está para o mundo contemporâneo. Em uma citação que faz do autor Martucelli, ele subscreve e enfatiza esse conceito:

A crise da visão da igualdade social sob influência de uma concepção totalizante da sociedade acarreta uma mudança profunda, formulada pela noção de equidade. Em sua formulação clássica, a igualdade enfatiza os elementos comuns aos indivíduos genéricos e não suas diferenças, seus particularismos coletivos. Ela remete sempre a uma concepção global e comum da sociedade. É diferente o que se dá com a noção de "equidade" que reconhece a pertinência política das especificidades culturais dos indivíduos e dos grupos, aceitando a ideia de um tratamento diferenciado dos membros dessas coletividades. (MARTUCELLI, 1996, p. 21 apud JESUS, 2011, p. 82)

A equidade está ligada também à identidade, pois são diferentes identidades que configuram as desigualdades, não somente a de classe social, mas a de gênero, de origem nacional, de cor e aparência física, por exemplo. Para Jesus (2011), a luta pela justiça não está ligada exclusivamente à igualdade, mas à equidade como uma luta "cultural", de desvelamento do processo de subalternização contra os negros, índios, mulheres, crianças. Essa luta cultural é empreendida pelos movimentos sociais que buscam reverter a situação de assimetria na sociedade.

Em escala internacional, podemos indicar a 3ํㅡㄹ Conferência Mundial contra 0 Racismo, a Discriminação Racial, a Xenofobia e Formas Correlatas de Intolerância, 
promovida pela Organização das Nações Unidas (ONU), em 2001, na cidade de Durban, na África do Sul, como um marco na luta pelas políticas de ações afirmativas, assim como um espaço de reflexão sobre possíveis rumos a serem tomados frente aos problemas gerados pela falta de equidade na concessão dos direitos.

Gomes (2011, p. 115), referindo-se à urgência de se lutar pela concretização da igualdade dos coletivos diversos tratados historicamente como desiguais, afirma que

ao colocar a diversidade étnico-racial e o direito à educação no campo da equidade, - Movimento Negro indaga a implementação das políticas públicas de caráter universalista e traz o debate sobre a dimensão ética da aplicação dessas políticas, a urgência de programas voltados para a efetivação da justiça social e a necessidade de políticas de ações afirmativas que possibilitem a efetiva superação das desigualdades étnico-raciais, de gênero, geracionais, educacionais, de saúde, moradia e emprego aos coletivos historicamente marcados pela exclusão e pela discriminação.

A citada autora chama a atenção em outro artigo (GOMES, 2003) para um aprofundamento desse debate, sendo que algumas iniciativas dos governos vêm merecendo destaque no atendimento às reivindicações desses movimentos, especialmente no tocante à educação.

\section{As ações afirmativas na educação superior o Brasil: desafios na promoção de equidade}

Para Gomes (2011), a educação no Brasil tem sido apontada pelos estudos, assim como pelos movimentos sociais, como um espaço onde persistem históricas desigualdades sociais e raciais, exigindo que o Estado estabeleça políticas e práticas específicas de superação desse quadro, políticas essas chamadas de Ações Afirmativas. No caso do acesso à educação superior, várias universidades públicas têm instituído sistemas especiais de ingresso em cursos de graduação dirigidos para estudantes negros, indígenas e oriundos do sistema público de ensino. Antes de adentrarmos nas referências de estudos que focalizam as ações voltadas à equidade no acesso à educação superior de universidades públicas, a partir da produção intelectual recente, teceremos considerações sobre algumas referências dessas políticas no cenário contemporâneo e no Brasil. 


\subsection{Reconhecimento de um direito à diversidade como um direito social}

Para Santos (2012), é recente a adoção de políticas de ações afirmativas no Brasil. São medidas para criar igualdade de oportunidades para grupos e populações socialmente excluídas, que preveem tratamento diferenciado, tendo em vista uma maior inserção em serviços como educação, saúde e trabalho. Para esse mesmo autor, a institucionalização de programas de ações afirmativas iniciou-se na Índia, quando foi implantado o sistema de cotas para castas. "Desde 1948, o sistema de cotas consta na Constituição desse país e se estende aos órgãos legislativos, ao serviço público e às instituições de ensino" (SANTOS, 2012, p. 402). Outros países também adotaram programas de ações afirmativas como medidas, que favorecem os segmentos sociais vulneráveis a processos de discriminação com relação ao acesso em serviços públicos, mercado de trabalho, serviços de saúde, representação em assembleias, cargos públicos, matrícula em estabelecimentos de ensino, notadamente cursos universitários e outros. Os beneficiários se estendem aos descendentes de povos ancestrais, aos negros, índios, mulheres, portadores de necessidades especiais e outros.

Para Travitzki e Raimundo (2012, p.79),

a ação afirmativa estaria ligada a sociedades democráticas que tenham no mérito individual e na igualdade de oportunidades seus principais valores [...], justificandose a desigualdade de tratamento no acesso aos bens e aos meios apenas como forma de restituir tal igualdade, devendo, por isso, tal ação ter caráter temporário dentro de um âmbito e escopo restrito.

No Brasil, a pressão dos movimentos sociais em prol do estabelecimento dessas medidas se acirrou entre os anos 1980 e 1990, tencionando a concepção do "mérito individual", que reserva exclusivamente ao mercado a definição da distribuição de riquezas e oportunidades para definir uma compreensão de que não existe, na prática, igualdade de oportunidades, e que, historicamente, a sociedade construiu relações de poder assimétricas que em nada advieram das competências dos indivíduos num mercado idealizado. A partir daí, observam-se significativas mudanças no cenário brasileiro, relativas à concessão dos direitos, considerando as diferenças e as desigualdades histórico-sociais.

Santos (2012), no entanto, lembra que as ações afirmativas já se faziam presentes na história brasileira, desde meados do século passado. Alguns dispositivos legais ou indicativos foram se estabelecendo como, por exemplo, a Lei 
dos dois terços para a reserva de trabalhadores nacionais em 1940; a proposta de reserva de vagas para trabalhadores negros, em 1968; a Lei 8.213/91 que estabelece um percentual de contratação de pessoas com necessidades especiais pelas empresas privadas; o estímulo indicado na Constituição Federal atual para a contratação de mulheres nas empresas; a Lei 9.100/96 que estabelece reserva de percentual mínimo para candidatura de mulheres em partidos políticos, dentre outros dispositivos. Nesse particular, pode-se lembrar também do julgamento recente do Supremo Tribunal Federal sobre a constitucionalidade dos programas de reserva de vagas, nas universidades públicas, para grupos vulneráveis às desigualdades sociais no Brasil.

No caso do direito à educação, o Movimento Negro, além de fomentar o debate em torno dessas questões, tem feito importante pressão sobre o governo, para que sejam adotadas medidas nos sistemas de ensino, com vistas à superação do racismo, especialmente nos estabelecimentos escolares. Dessa forma, algumas intervenções vêm sendo definidas na legislação, de forma a atender às reivindicações dessa população. Exemplo disso foi a aprovação da Lei no 10.639/03, posteriormente alterada pela Lei $\mathrm{n}^{\circ}$ 11.645/08, que inclui no currículo oficial das escolas de educação básica os conteúdos de história e cultura afro-brasileira e indígena. As políticas de reserva de vagas nas universidades também se fortaleceram nessa mobilização e debate social.

Assim, com base nessas discussões acerca dos avanços na definição dos direitos humanos e nas concepções de igualdade, verifica-se que, a partir desse período, no Brasil, as universidades públicas, pressionadas por movimentos sociais e sociedade civil organizada, iniciaram o processo de implantação de políticas de ações afirmativas para o ingresso de parcelas da população historicamente excluídas. De acordo com Cardoso (2008), os movimentos reivindicatórios das minorias reabriram as discussões sobre as desigualdades sociais na educação superior, na perspectiva da questão racial.

Mais recentemente, no nível do sistema federal de ensino, em agosto de 2012, foi aprovada a Lei o 12.711 , a qual determina que as instituições federais de educação superior reservem, no mínimo, $50 \%$ de suas vagas para ingresso em cursos de graduação, de estudantes que tenham cursado integralmente o ensino médio em escolas públicas. Certamente, essas transformações que vêm ocorrendo 
nas universidades públicas a partir das políticas de ações afirmativas requerem análises de seus efeitos, tendo em vista a garantia do direito à Educação e a existência de uma multiplicidade de dados não analisados sobre as experiências em andamento.

\subsection{Alguns estudos que focalizam ações afirmativas nas políticas de expansão do acesso em universidades públicas no Brasil}

$\mathrm{Na}$ produção acadêmica sobre ações afirmativas e educação, merece destaque a literatura recente sobre ações desenvolvidas no sentido de ampliar o acesso à educação superior a jovens tradicionalmente excluídos dos processos seletivos. Essas ações, promovidas por universidades públicas em parceria com órgãos públicos ou organizações não governamentais indicam uma ampliação do interesse sobre essa temática e uma crescente preocupação com políticas efetivas de equidade. São dignos de nota os estudos de Feres Júnior, Daflon e Campos (2011); Borges e Carnielli (2005); Tragtenberg, Bastos, Nomura e Peres (2006); Carvalho (2006); Mitrudis e Penin (2006); Rosistolato, Helayël-Neto e Xavier (2011); Bastos, Gomes, Fernandes e França (2012), dentre outros.

Os estudos consultados para a elaboração deste artigo, ora tendem a analisar a temática de forma mais abrangente, fazendo investigações de caráter documental e utilizando técnicas estatísticas para caracterizar os fenômenos, ora tomam como foco realidades localizadas, a partir de programas específicos. Na primeira perspectiva, os autores têm realizado levantamentos da produção acadêmica que analisam experiências de implantação de programas ou fazem estudos com abordagem quantitativa, caracterizando as ações desses programas. $\mathrm{Na}$ segunda perspectiva, os autores relatam investigações sobre experiências pontuais, que podem ser classificadas como aquelas em que são adotadas as políticas de reserva de vagas e aquelas em que são adotados os sistemas de bônus. Também no bojo dessa produção, destacam estudos que focalizam a implantação de programas de acréscimos de vagas que atendem a grupos socioculturais específicos.

\subsubsection{Estudos que analisam a temática de forma mais abrangente}

Nesta categoria ressaltam as produções de Souza e Portes (2011), Daflon, Feres Júnior e Campos (2013), Travitzki e Raimundo (2012) e Santos (2012). Souza 
e Portes (2011) analisam documentos que versavam sobre a implantação das políticas/ações afirmativas em 59 instituições federais de ensino superior, buscando compreender os aspectos legais do processo de implantação das políticas voltadas para o ingresso de estudantes. Das instituições analisadas no estudo, 64\% adotaram essas políticas. Neste estudo, verifica-se uma variedade de modelos em torno da implantação dessas ações nas instituições pesquisadas. As divergências observadas, que comportam singularidades nas formas de empreender os sistemas de reserva de vagas, se revelam nos distintos percentuais adotados, nas metodologias e na definição dos beneficiários, dentre outros. Para as autoras, essas diferenças são construídas no jogo de forças que se estabeleceram em cada realidade.

Os achados deste estudo permitem observar que as universidades, apesar de cederem aos argumentos favoráveis à implantação das políticas/ações afirmativas,

preservaram-se ao não adotar uma política fundada exclusivamente no conceito de raça, revelando uma clara opção por um modelo misto, o sociorracial, da ordem de $89 \%$ (somadas aqui a reserva sociorracial e a social), mais ao gosto de todos, modelo que enfrenta menos resistência nos meios acadêmicos e científicos. (SOUZA;PORTES, 2011, p. 526)

Outro dado importante nessa análise é que apenas $26 \%$ dos documentos investigados mencionam medidas voltadas à permanência/assistência dos estudantes. Esse estudo permite mostrar uma visão ampliada das ações das instituições federais de ensino superior, revelando, em 2011, que dois terços dessas instituições adotaram algum tipo de ação afirmativa para ingresso de estudantes em cursos de graduação, beneficiando, principalmente, estudantes de escolas públicas.

Nessa mesma direção, os estudos de Daflon, Feres Júnior e Campos (2013) buscam traçar um panorama do estado das políticas de inclusão no ensino superior público. Argumentam sobre a necessidade de avançar em direção a um retrato mais abrangente e detalhado da ação afirmativa nesse nível de ensino e, como contribuição, apresentam os principais resultados de um levantamento das características das ações afirmativas das universidades públicas brasileiras. Os autores se baseiam numa análise de documentos, que instituíram e regulamentaram as ações afirmativas em vigência em mais de 70 das 96 universidades públicas estaduais e federais do país. Dentre os aspectos analisados, destacam-se os tipos de normas que regulamentam essas políticas, seus beneficiários, critérios de 
seleção e potencial inclusivo, bem como o perfil regional e acadêmico das instituições que as adotam.

Daflon, Feres Júnior e Campos (2013), ao se referirem as iniciativas para a adoção de políticas de ações afirmativas, apontam que 77\% surgem dos próprios conselhos universitários, sendo $23 \%$ resultados de leis estaduais que incidiram sobre instituições estaduais de ensino superior. Chamam a atenção as formas como surgiram as demandas institucionais que tiveram variação significativa, que vão desde as pressões dos movimentos sociais locais, a organização dos docentes nas universidades, o empenho dos núcleos de estudos afro-brasileiros, dentre outros. Ao tecerem considerações sobre o caráter descentralizado dessas políticas, os autores apontam "a contribuição dos membros das instâncias locais com uma experiência técnica de primeira mão e a não sujeição das políticas públicas a regras que ignoram as particularidades locais" (2013, p. 309). Todavia, apontam também certas desvantagens, por conta da falta de integração entre essas iniciativas, "bem como a ausência de critérios claros e de comum conhecimento para a fruição do benefício, até problemas concernentes à concepção, planejamento e execução das políticas" (2013, p. 309).

Os resultados da referida pesquisa convergem com os encontrados por Souza e Portes (2011), quando destacam a predominância das políticas que adotaram o critério social em sua implantação. Daflon, Feres Júnior e Campos (2013) observam que 85\% das universidades que adotaram ações afirmativas têm os alunos de escolas públicas como os maiores alvos dessas políticas. Em segundo, vêm os pretos e pardos, com $58 \%$, e em terceiro lugar, aparecem os indígenas como contemplados em $51 \%$ dessas universidades. Em percentuais menores, aparecem os portadores de deficiência e participantes de programas de formação em licenciatura indígena e outros grupos, como nativos do estado ou do interior do estado em que a universidade se localiza, professores da rede pública, originários de comunidades remanescentes de quilombos, filhos de agentes públicos mortos ou incapacitados em serviço e mulheres. Com base nos dados analisados, os autores concluem que as "percepções das desigualdades de classe são mais relevantes do que as desigualdades raciais entre os articuladores das ações afirmativas no nível local, seja nos conselhos universitários, seja nas assembleias legislativas". Porém, salientam que essa diversidade tende a diminuir com a implementação, planejada 
para quatro anos, da Lei n. 12.711, aprovada em 2012 (DAFLON; FERES JÚNIOR; CAMPOS, 2013, p. 324). Assim como essa pesquisa, vale o registro de outros estudos (FERES JÚNIOR et al., 2013b; DAFLON; FERES JÚNIOR; GABRIELA, 2014), realizados pelo Grupo de Estudos Multidisciplinares da Ação Afirmativa (Gemaa), que vem contribuindo de forma significativa para o debate sobre as ações afirmativas em universidades brasileiras.

Travitzki e Raimundo (2012), com base nos dados do Censo de Educação Superior (CES-2009), investigam as diferenças entre cotistas e não cotistas, no que diz respeito à realização de atividades extracurriculares nas Instituições de Ensino Superior (IES). Os autores discorrem sobre aspectos históricos e conceituais das políticas de ações afirmativas, citando como exemplo o caso da Unicamp, que implantou o sistema de bônus para estudantes oriundos de escolas públicas, negros e indígenas. Essa universidade foi a primeira a adotar esse sistema, em 2005, através do Programa de Ações Afirmativas e Inclusão Social (Paais), cujos objetivos estão relacionados à excelência acadêmica e não apenas aos princípios de igualdade e de inclusão, conforme dados apurados pelos autores. Eles distinguem, assim, o sistema de cotas utilizado pela maioria das universidades que adotaram ações afirmativas de acesso, do sistema de bônus. Enquanto as cotas definem percentuais fixos de vagas para determinados grupos socialmente desfavorecidos, o sistema de bônus adiciona pontos extras ao desempenho dos candidatos no vestibular, de forma que "a proporção de beneficiados possa variar a cada ano de acordo com o mérito", conforme foi implantado na Unicamp (TRAVITZKI; RAIMUNDO, 2012, p. 81).

Jocélio Santos, em artigo publicado em 2012, apresenta um levantamento e análise da produção intelectual existente sobre o tema, enfatizando os artigos publicados entre os anos de 2001 e 2011, e conclui que cresceu a produção bibliográfica sobre a adoção de ações afirmativas no ensino superior, traduzida, principalmente em teses de doutorado e dissertações de mestrado, defendidas em programas de pós-graduação e artigos de revistas especializadas. Durante esse período, 232 trabalhos foram encontrados, sendo 142 artigos, 71 dissertações e 19 teses, e a fase mais intensa dessa produção foi entre os anos de 2005 e 2010 . O autor analisa também dados da Universidade Federal da Bahia (UFBA) com relação ao rendimento dos alunos, dividindo em cotistas e não cotistas, com base no 
primeiro contingente de estudantes que ingressou por meio do sistema de cotas em 2005. O autor compara rendimentos no segundo semestre de 2005 e primeiro semestre de 2009 e verifica a situação desses dois grupos com relação à reprovação por falta. Os dados apontam que a maioria dos estudantes cotistas já cursou a maior parte dos componentes curriculares. Além disso, "a observação dos coeficientes de rendimento nos dois momentos analisados - o segundo e o nono semestres - evidencia um aumento significativo no contingente de estudantes cotistas com faixa de rendimento mais elevada - entre 7,0 e 10,0 pontos - ao longo do curso" (SANTOS, 2012, p. 411). Com relação à reprovação por falta, os dados indicam que, em $63,6 \%$ dos cursos, os estudantes cotistas estiveram menos sujeitos a esse tipo de reprovação.

\subsubsection{Estudos sobre programas específicos de reserva de vagas}

O artigo de Doebber e Grisa (2011) discute a política de ações afirmativas, tendo o critério racial também como orientador para a reversão das desigualdades étnico-raciais, a partir da experiência da Universidade Federal do Rio Grande do Sul (Ufrgs). Apesar de reconhecer os avanços com relação à ampliação desse percentual, o artigo faz críticas à forma como foi definida a seleção dos ingressos por esse sistema na Ufrgs. Segundo Doebber e Grisa (2011), esse modelo de reserva de vagas nessa universidade mantém a desigualdade no acesso, pois o ponto de corte não permite a entrada significativa de estudantes negros, principalmente em cursos de alto prestígio. Por outro lado, no que diz respeito ao que se tem denominado de cota social, os autores sinalizam que as mudanças nas formas de ingresso nos cursos de graduação da Ufrgs têm modificado o cenário, pois quase metade dos ingressos é oriunda de escolas públicas. Além disso, são apontadas ações da universidade em favor da permanência de estudantes, por meio da assistência estudantil.

Silva, Pinezi e Zimerman (2012) analisam a experiência das políticas de ações afirmativas desenvolvidas pela Universidade Federal do ABC (Ufabc). Nessa universidade, a implantação das cotas se distinguiu de outras universidades brasileiras, pois foram implantadas no primeiro vestibular realizado nessa instituição, em 2007. Na seleção das primeiras turmas, foi destinado o percentual de $50 \%$ das vagas para estudantes que cursaram a escola pública. Desse percentual, foram 
destinadas $27,3 \%$ das vagas para negros $0,1 \%$ para índios. Com relação ao apoio à permanência de estudantes cotistas, observaram que não "há ações específicas para os alunos que ingressaram por meio do sistema de cotas sociais e raciais" (SILVA; PINEZI; ZIMERMAN, 2012, p. 152). Os critérios de seleção para os programas assistenciais ou de iniciação científica não consideram o sistema de ingresso e parece resultar da falta de debates mais aprofundados acerca das políticas de ações afirmativas na Ufabc. O artigo leva à reflexão sobre a necessidade das políticas de cotas estarem associadas a outras políticas de ações afirmativas, como de apoio à permanência de estudantes e políticas universalistas. $\mathrm{Na}$ opinião dos autores, a experiência da Ufabc demonstra que a adoção do sistema de reserva de vagas não é suficiente para a diversificação da base social do ensino superior, mas pode contribuir para a promoção de mudanças na estrutura institucional e organizacional.

Maciel (2012) aborda a implantação das Ações Afirmativas na Universidade Federal do Maranhão (UFMA), que se deu por meio do sistema de reserva de vagas para negros, iniciado em 2006. A autora discorre sobre a trajetória das mobilizações que levaram à implantação do programa nessa universidade, destacando a atuação do Núcleo de Estudos Afro-Brasileiros (Neab), o qual apresentou e negociou a proposta junto à Reitoria. Esse grupo, formado por professores e estudantes, que se caracteriza por desenvolver pesquisas acadêmicas voltadas para o estudo da cultura afro-brasileira, desempenhou papel central nas negociações e definição do projeto na UFMA. Assim, em 2006, foi aprovada a reserva de vagas, com o percentual de $50 \%$ para as seguintes categorias: negros, indígenas, portadores de necessidades especiais e oriundos de escolas públicas. O autor argumenta que a política de ações afirmativas na UFMA foi voltada "exclusivamente para a ampliação quantitativa do acesso dos grupos beneficiários do sistema de cotas" (MARCIEL, 2012, p. 209).

Os estudos de Velloso e Cardoso (2011) sugerem uma reflexão acerca das políticas universalistas associadas a políticas de ações afirmativas na educação superior. Ao buscar verificar as chances de ingresso de candidatos negros na UnB, caso inexistisse o sistema de cotas, em processos seletivos no quinquênio 2004 2008, os autores afirmam que as cotas se revelaram como uma "poderosa alavanca para ampliar as chances de ingresso de jovens negros na UnB" (p. 240). Além disso, utilizando o artifício da simulação, os autores verificam que os efeitos do sistema de 
cotas para ingresso de estudantes negros se assemelham aos efeitos de uma política universalista, que proporcionasse a duplicação do número de vagas na referida universidade.

\subsubsection{Estudos sobre programas de bônus}

Peixoto e Braga (2012), em pesquisa realizada sobre os efeitos do programa de bônus para ampliação do acesso de estudantes de escola pública e de negros na Universidade Federal de Minas Gerais (UFMG), abordam as ações afirmativas na perspectiva da inclusão social e étnico-racial na educação superior. Em 2009, a UFMG aprovou, por quatro anos, a aplicação de bônus adicionais ao desempenho no vestibular para estudantes oriundos de escolas públicas e candidatos que se autodeclarassem pretos ou pardos. Para os primeiros, foi concedido o acréscimo de $10 \%$ sobre a nota no vestibular e, para os segundos, o percentual de $15 \%$. Com base nos resultados dos vestibulares e nos dados dos questionários socioeconômicos preenchidos pelos candidatos, os autores analisaram as alterações ocorridas na composição socioeconômica e étnica de candidatos e dos aprovados, nos anos 2009 e 2010. A análise aponta para uma ampliação do número de estudantes de escolas públicas e que se declararam pretos ou pardos. Os resultados desvelam os efeitos positivos da implantação do sistema de bônus, para favorecer a entrada de estudantes oriundos de escolas públicas e negros, bem como daqueles com renda inferior a cinco Salários Mínimos (SM).

Os autores ainda acrescentam que para o aprimoramento dessa proposta, "precisam ser implementadas ações de assistência estudantil, indispensáveis para apoiar o desempenho do estudante beneficiado durante sua permanência na universidade" (PEIXOTO; BRAGA, 2012, p. 186).

O Programa de Inclusão Social da Universidade de São Paulo (Inclusp) iniciou-se em 2007. A análise dos impactos dessa experiência é apresentada por Matos et al (2012), em um artigo que discute a implantação desse sistema na ótica da inclusão. Ao abordarem as ações afirmativas como estratégias de inclusão social, os autores verificaram que apenas $24,7 \%$ dos ingressantes nessa universidade tinham cursado o ensino médio em escolas públicas até 2007. A partir dessa constatação, a USP estabeleceu um sistema de pontuação acrescida para os candidatos que comprovassem ter cursado o ensino médio em instituições públicas. 
De maneira geral, em 2007 e 2008, o bônus foi de 3\% para os referidos estudantes. A partir de 2009, os estudantes com esse perfil, além de terem esse percentual, foram acrescentados outros percentuais, decorrentes do desempenho desses estudantes no Exame Nacional do Ensino Médio (Enem); e no Programa de Avaliação Seriada da USP (Pasusp). Essas novas medidas proporcionaram um acréscimo significativo, de até $12 \%$, para estudantes oriundos de escolas públicas, a depender de seu desempenho nessas provas.

Ao sinalizarem o crescimento do número de vagas na USP, os autores mencionam o decréscimo do número de candidatos de escolas públicas inscritos no vestibular dessa universidade nos últimos anos, associando esse aspecto a fatores como o crescimento das universidades públicas e de programas de bolsas em instituições privadas ofertadas pelo Governo Federal. Assim, de acordo com Matos et al (2012), mesmo verificando a diminuição do número de inscritos no vestibular, nos anos 2001-2010, observa-se o aumento do número de aprovados que cursaram o ensino médio em escolas públicas e associam esse crescimento ao programa de inclusão da universidade.

\subsubsection{Estudos sobre programas de acréscimo de vagas para demandas específicas}

Marques, Franco e Schlindwein (2011) apresentam e discutem a experiência de um curso de "agronomia com ênfase em agroecologia em sistemas rurais sustentáveis", voltado para a agricultura familiar, atendendo assentados da reforma agrária no estado de São Paulo, em desenvolvimento pela Universidade Federal de São Carlos (Ufscar), campus Sorocaba, como sendo a materialização de uma ação afirmativa. Para eles, "é uma experiência que traz sentido emblemático de um rumo diferenciado que pode estar se iniciando para a universidade pública brasileira: receptividade a outras camadas da população excluídas da educação de qualidade, da educação superior" (MARQUES; FRANCO; SCHLINDWEIN, 2011, p. 562).

Nesse sentido, para esses autores, os movimentos sociais do campo têm se firmado na luta por educação e acesso ao ensino superior. São apontados, ainda, indicadores positivos desse curso, pois, no decorrer de cinco anos, verificou-se um baixo número de abandono, mesmo com as dificuldades de funcionamento, problemas de transporte, dentre outros. Observa-se que a experiência desse curso 
"fortalece a convicção de que é necessário repensar e, mais do que isso, redefinir os critérios de acesso ao ensino superior público e as formas de apoio ao estudante" (MARQUES; FRANCO; SCHLINDWEIN, 2011, p. 574).

Freitas (2011) discorre sobre as políticas de acesso dos povos indígenas a educação superior, por meio do Instituto Insikiran da Universidade Federal de Roraima (UFRR), mostrando como se realizam as atividades didático-pedagógicas dos cursos de licenciatura intercultural e gestão territorial indígena. A UFRR é a primeira instituição federal de ensino superior a implantar um curso específico de graduação para esse público, constituído de egressos do magistério (ensino médio) e de todos os que estão atuando nas escolas indígenas, no sentido de dar continuidade aos seus estudos. Além de formar professores indígenas nesse nível, a iniciativa propicia o acesso à universidade de uma população historicamente excluída. Devido às pressões dos movimentos sociais indígenas de Roraima, foram criadas, ainda, vagas nos demais cursos da UFRR, o que revela certos avanços no cenário brasileiro com relação à diminuição das desigualdades de acesso dos índios à educação superior.

\section{Considerações finais}

As ações afirmativas ou discriminação positiva têm como finalidade proporcionar igualdade de condições para grupos socialmente marginalizados. Elas se configuram como parte de ações para efetivação dos direitos sociais e são resultados de um processo de conquistas de diversos grupos. A crescente adesão de instituições de ensino superior às políticas de ações afirmativas de ingresso e permanência de estudantes desses grupos indica a assimilação da concepção de reparação e justiça social e, em menor escala, de respeito à diversidade.

Com o intuito de possibilitar a redução das desigualdades de acesso e permanência de estudantes oriundos de escolas públicas, negros e indígenas, os programas de reserva de vagas e a concessão de bônus no vestibular e o acréscimo de vagas para determinados grupos, em universidades públicas, têm se inserido como uma política de ação afirmativa. As iniciativas das universidades brasileiras visam a modificar o processo de seleção de estudantes para os cursos de graduação, até então, amparado, exclusivamente, pelo critério da classificação por desempenho. 
Desse modo, esses programas se inserem nesse contexto de mobilizações, debates e ações do Estado, em favor de políticas de promoção da efetiva igualdade, perspectivas que vão em direção àquelas definidas nos direitos humanos. Discutir a implementação de políticas de ações afirmativas requer a compreensão de seus efeitos com vistas à análise da efetivação do princípio da equidade.

$\mathrm{O}$ reconhecimento do direito à diversidade e à diferença, as lutas pela conquista desse direito e as análises sobre as políticas adotadas nesse sentido têm suscitado o desenvolvimento de uma produção acadêmica nos últimos anos, que revela a relevância do debate e da necessidade de intervenções para provocar mudanças no quadro das desigualdades sociais.

A produção intelectual aqui analisada traz alguns indicativos de como vêm sendo implantadas as políticas nesse sentido. Podemos enumerar alguns pontos que se destacam nessa análise:

1. As universidades públicas brasileiras, de uma maneira geral, encontram-se sensíveis às questões históricas relativas às limitações dos direitos a grupos e estão avançando em termos de implantação de medidas para a diminuição das injustiças do acesso à educação superior desses grupos.

2. Na implementação das políticas anteriormente mencionadas, existe uma variedade de modelos de programas, que tendem a ser aperfeiçoados com as experiências e com as reflexões, feitas a partir dos resultados preliminares.

3. Alguns estudos ressaltam a importância dos movimentos sociais na luta pelo avanço dos direitos, empreendendo pressão junto ao Estado, no sentido de alargarem as possibilidades de conquistas.

4. As universidades enfrentam agora os desafios para o aprimoramento das medidas adotadas, em função de avaliações, principalmente com relação ao acompanhamento dos estudantes, em termos de assistência e infraestrutura, de modo a alcançar resultados mais positivos das ações.

5. A comunidade acadêmica tem investido em estudos nessa direção, e os textos analisados têm demonstrado a pertinência dos programas implantados, com resultados importantes. 
Além disto, com base nas discussões analisadas, podemos inferir que a garantia do acesso não é suficiente para a inserção no ensino superior. A permanência com qualidade e a pós-permanência precisam ser pensadas como estratégias no âmbito das políticas públicas, para que, de fato, o direito à educação superior seja assegurado a todos os cidadãos.

Apesar de compreendermos a necessidade das políticas afirmativas, considera-se que a adoção concomitante de políticas universalistas é essencial na sociedade brasileira, especialmente na educação superior, como pré-condição para favorecer a democratização do acesso. O Censo Escolar de 2006 do Inep-MEC já informava que, naquele ano, apenas $10 \%$ dos jovens de 18 a 24 anos estavam na educação superior (BRASIL, 2007). A Argentina apresentava, em 2006, um percentual próximo de $40 \%$. Venezuela, Uruguai e Costa Rica tinham pouco mais de $30 \%$. O Peru tem mais jovens em suas universidades que o Brasil e, juntamente com o Chile, apresentava $20 \%$ de seus jovens no ensino superior (BRASIL, 2007).

Esses dados indicam a necessidade da ampliação da rede de ensino superior pública, para atender à imensa maioria dos jovens que não têm condições de pagar as mensalidades das faculdades particulares. A comparação da situação brasileira com a de outros países permite perceber como o próprio desenvolvimento econômico e social fica limitado pela pouca presença de profissionais de nível superior. Por isso, as políticas universalistas e as políticas de ações afirmativas não são excludentes e podem ser combinadas.

É necessária a expansão do sistema, para que maiores proporções dos jovens brasileiros tenham acesso à educação superior. Essa concepção de que as ações afirmativas são um aprimoramento das políticas públicas para promover a justiça social e não estão em contradição com as políticas universalistas está presente em Siss (2003). Para esse autor (2003, p. 111),

leis ou intervenções políticas que compreendam ações do Estado, voltadas para determinados grupos específicos, os quais foram e são colocados em desvantagem, quando acompanhadas de ações universalistas, podem ser extremamente úteis para reduzir os altos índices de desigualdades existentes entre os grupos, como, por exemplo, os brancos e os afro-brasileiros. Eles podem concorrer, como o apontam os resultados de sua aplicação em outros países, para equiparar ambos os grupos na raia de competição por bens materiais e simbólicos em momentos específicos.

Nesse sentido, o Brasil também tem adotado algumas políticas universalistas, na direção de ampliar o acesso às políticas públicas, inclusive na educação. Essa expansão mudou a situação de haver apenas $7,1 \%$ dos jovens de 18 a 24 anos 
cursando uma formação universitária, em 1997, para termos 17,8\% em 2011, segundo dados do Inep (BRASIL, 2012). E essa proporção é muito distinta entre as regiões do país. Enquanto no sudeste, há 22,1\% dos jovens de 18 a 24 anos em cursos superiores, apenas $11,9 \%$ dos jovens dessa faixa etária estão nesses cursos, nas regiões norte e nordeste. No centro-oeste, os estudantes universitários chegam a 23,9\% dos jovens, o que é mais do que dobro do que há no norte e nordeste. Nota-se que a adoção exclusivamente de programas de ações afirmativas num reduzido universo de instituições de ensino superior não mudará também o acesso mais massivo e democrático a esse nível de educação pelas diferentes classes sociais, e, por isso, podemos considerar que a complementaridade entre esses dois tipos de política é fundamental.

As ações afirmativas e a expansão das universidades públicas significam o reconhecimento de direitos sociais, a necessidade de sua expansão e a compreensão de que o processo histórico e social coloca os indivíduos em posições diferentes, o que requer oportunidades diferenciadas para o alcance da igualdade na realidade social vivenciada pelos indivíduos.

\section{Referências bibliográficas}

BASTOS, M. D. F.; GOMES, M. de F. C. M.; FERNANDES, L. L.; FRANÇA, B. A. Políticas públicas complementares para a inclusão social: uma análise do prévestibular social. Revista Brasileira de Estudos Pedagógicos, v. 93, n. 233, p. 51-76, jan./abr. 2012.

BORGES, J. L. G.; CARNIELLI, B. L. Educação e estratificação social no acesso Universidade pública. Cadernos de Pesquisa, v. 35, n. 124, p. 113-139, 2005.

BRASIL. Ministério da Educação. Instituto Nacional de Estudos e Pesquisas Educacionais - INEP. Apresentação do Ministério na Comissão de Educação do Senado Federal, em fevereiro de 2013. Brasília: Ministério da Educação, 2007.

Disponível Resultados do Censo da Educação Superior 2012. Tabela

<www.inepgovbr/informacoes estatisticas/indicadores educacionais/2014/apresent acao_efa_29012014.pdf. Acesso em: 09 ago. 2014.

CARDOSO, C. B. Efeitos da política de cotas na Universidade de Brasília: uma análise do rendimento e da evasão. Brasília, 2008. Dissertação (Mestrado em Educação) - Universidade Federal de Brasília. Brasília, 2008. Disponível em: <http://repositorio.bce.unb.br/handle/10482/1891>. Acesso em: 20 jun. 2011.

CARVALHO, J. C. B. Os cursos pré-vestibulares comunitários e seus condicionantes pedagógicos. Cadernos de Pesquisa, v.36, n.128, p. 299-326, 2006. 
CARVALHO, L. M.; PAIXÃO, M. Relatório anual das desigualdades raciais no Brasil; 2007-2008. Rio de Janeiro: Editora Garamond, 2008.

CASHMORE, Ellis. Dicionário de relações étnicas e raciais. São Paulo: Summus, 2000.

DAFLON, V. T.; FERES JÚNIOR, J.; CAMPOS, L. A. Ações afirmativas raciais no ensino superior público brasileiro: um panorama analítico. Cadernos de Pesquisa. v.43, n.148, p.302-327, jan./abr. 2013.

MORATELLI, G. Levantamento das políticas de ação afirmativa 2014: evolução temporal e impacto da Lei ㄲo 12.711 sobre as universidades federais (lesp-Uerj). Levantamento das políticas de ação afirmativa (Gemma). n. 4, p. 1-10, 2014.

Disponível em: <http://gemaa.iesp.uerj.br/files/Levantamento_federais_2014b.pdf>. Acesso em: 30 ago. 2014.

DOEBBER, M. B.; GRISA, G. D. Ações afirmativas: o critério racial e a experiência da Universidade Federal do Rio Grande do Sul. Revista Brasileira de Estudos Pedagógicos, v. 92, n.232, p. 577-598, 2011.

DRAY, Guilherme Machado. O princípio da igualdade no direito do trabalho. Coimbra: Livraria Almedina, 1999.

FERES JÚNIOR, J. Comparando justificações das políticas de ação afirmativa: Estados Unidos e Brasil. Estudos Afro-Asiáticos, v.29, p. 63-84, 2007.

; CAMPOS, L. A. Liberalismo igualitário e ação afirmativa: da teoria moral à política pública. Revista de Sociologia e Política, v. 21, n. 48, p. 85-99, dez. 2013.

; DAFLON, V.; CAMPOS, L. A. A ação afirmativa no ensino superior brasileiro (2011). Levantamento das políticas de ação afirmativa (Gemma). Rio de Janeiro: lesp-Uerj, 2011. p. 1-20.

Ação afirmativa no ensino superior brasileiro hoje: análise institucional. Rio de Janeiro: Uerj; Gemma; lesp, 2010.

; BARBARELA, E.; RAMOS, P. Levantamento das políticas de ação afirmativa nas universidades estaduais (2013). Levantamento das políticas de ação afirmativa (Gemma). Rio de Janeiro: lesp-Uerj, 2013b. p. 1-25.

FREITAS, M. A. B. O Instituto Insikiran da Universidade Federal de Roraima: trajetória das políticas para a educação superior indígena. Revista Brasileira de Estudos Pedagógicos, v.92, n.232, p. 599-615, 2011

GOMES, J. B. O Debate Constitucional sobre as ações afirmativas. In: SANTOS, Renato Emerson: LOBATO, Fátima (Orgs.). Ações afirmativas: políticas públicas contra as desigualdades raciais. Rio de Janeiro: DP\&A, 2003. p. 15-57.

GOMES, J. B. Ação afirmativa e princípio constitucional da igualdade: o direito como instrumento de transformação social. A experiência dos EUA. Rio de Janeiro: Renovar, 2001.

; SILVA, F. D. L. L. As ações afirmativas e os processos de promoção da igualdade efetiva. In: SEMINÁRIO INTERNACIONAL AS MINORIAS E O 
DIREITO, 2001, Brasília. Anais... Brasília: CJF, 2003. (Série Cadernos do CEJ, v. 24).

Disponível em: <http://daleth.cjf.jus.br/revista/SerieCadernos/Vol24/artigo04.pdf>. Acesso em: 30 ago. 2014.

GOMES, N. L. Diversidade étnico-racial, inclusão e equidade na educação brasileira: desafios, políticas e práticas. Revista Brasileira de Política e Administração da Educação, v.27, n.1, p. 109-121, jan.- abr. 2011.

GUIMARÃES, A. S. A. Cidadania e retóricas negras de inclusão social. São Paulo: Lua Nova, 2012.

JESUS, R. E. Ações afirmativas, educação e relações raciais: conservação, atualização ou reinvenção do Brasil? Belo Horizonte: UFMG/FaE, 2011.

LIMA, Lana Ferreira de. A relação entre a cidadania e o direito à igualdade: a face positiva e negativa. Educação em Revista, v.10, n.2, p.87-102, jul.-dez. 2009.

LIMA, S. P. RODRIGUEZ, M. V. Políticas educacionais e equidade: revendo conceitos. Contrapontos (Univali), v. 8, p. 53-69, 2008. Disponível em: <http://siaiweb06.univali.br/seer/index.php/rc/article/view/936>. Acesso em: 03/07/ 2013.

MACIEL, R. O. Ações afirmativas na Universidade Federal do Maranhão. Revista Brasileira de Estudos Pedagógicos, v. 93, n. 233, p. 189-214, jan./abr. 2012.

MARQUES, W.; FRANCO, F. S.; SCHLINDWEIN, M. N. Universidade e movimentos sociais no Brasil: uma experiência de ação afirmativa. Revista Brasileira de Estudos Pedagógicos, v. 92, n. 232, p. 557-576, set./dez. 2011.

MATOS, M. S.; PIMENTA, S. G.; ALMEIDA, M. I. de; OLIVEIRA, M. A. de C. O impacto do Programa de Inclusão Social da Universidade de São Paulo no acesso de estudantes de escola pública ao ensino superior público gratuito. Revista Brasileira de Estudos Pedagógicos , v.93, n. 235, p. 720-742, set./dez. 2012.

MITRULIS, E.; PENIN, S. Pré-vestibulares alternativos: da igualdade à equidade. Cadernos de Pesquisa, v. 36, n. 128, p. 269-298, 2006.

PEIXOTO, M.do C. de L. e BRAGA, M. M. Ações afirmativas no ensino superior e o programa de bônus para ingresso nos cursos de graduação da Universidade Federal de Minas Gerais. Revista Brasileira de Estudos Pedagógicos, v. 93, n. 233, p. 166188, 2012.

PIOVESAN, F. Ações afirmativas da perspectiva dos direitos humanos. Cadernos de Pesquisa, v. 35, n. 124, p. 43-55, jan./abr. 2005.

ROSISTOLATO, R. P. da R.; HELAYEL-NETO, J. A.; XAVIER, M. D. da S. Juventudes populares em um pré-vestibular: a construção coletiva de expectativas e campos de possibilidades educacionais. Revista Brasileira de Estudos Pedagógicos , vol.92, n. 232, p. 616-638, 2011.

SANTOS, J. T. dos. Ações afirmativas e educação superior no Brasil: um balanço crítico da produção. Revista Brasileira de Estudos Pedagógicos, v. 93, n. 234, [número especial], p. 401-422, maio/ago. 2012. 
SILVA, S. J. da; PINEZI, A. K. M.; ZIMERMAN, A. Ações afirmativas e inclusão regional: a experiência da Universidade Federal do ABC. Revista Brasileira de Estudos Pedagógicos, v.93, n.233, p. 147-165, 2012.

SISS, A. Afro-brasileiros, cotas e ação afirmativa: razões históricas. Rio de Janeiro: Quartet, 2003.

SOUSA, L. P; PORTES, É. A. As propostas de políticas/ações afirmativas das universidades públicas e as políticas/ações de permanência nos ordenamentos legais. Revista Brasileira de Estudos Pedagógicos, v. 92, n. 232, p. 516-541, set./dez. 2011.

TRAGTENBERG, M. H. R.; BASTOS, J. L. D.; NOMURA, L. H.; PERES, M. A. Como aumentar a proporção de estudantes negros na universidade? Cadernos de Pesquisa, v.36, n.128, p. 473-495, 2006.

TRAVITZKI, R.; RAIMUNDO, R. L. G. Alunos cotistas e atividades extracurriculares: análise do Censo da Educação Superior 2009. Revista Brasileira de Estudos Pedagógico, v.93, n. 233, p. 77-95, 2012.

VELLOSO, J.; CARDOSO, C. B. Um quinquênio de cotas: as chances de ingresso de negros na Universidade de Brasília. Revista Brasileira de Estudos Pedagógicos, v. 92, n. 231, p. 221-245, maio-ago. 2011. 